\title{
PENGARUH PENGGUNAAN LARUTAN DAUN BANDOTAN (Ageratum conyzoides) TERHADAP KADAR GLUKOSA DARAH IKAN KOI (Cyprinus carpio) PASCA TRANSPORTASI
}

\section{INFLUENCE USE OF BANDOTAN (Ageratum conyzoides) TO RATE KOI FISH (Cyprinus carpio) BLOOD GLUCOSE AFTER TRANSPORTATION}

\author{
Laksmi Sulmartiwi, Sri Harweni, Akhmad Taufiq Mukti dan Rr. Juni Triastuti \\ Fakultas Perikanan dan Kelautan Universitas Airlangga \\ Kampus C Mulyorejo - Surabaya, 60115 Telp. 031-5911451
}

\begin{abstract}
Transportation makes stress for fish because of high density and decreasing of water quality. Stress can increase blood glucose. Bandotan have Ca blocking effect. The Ca blocking effect occur in reticulum endoplasmic in smooth muscle. This research aimed to identify bandotan leaf effect in transport medium on blood glucose of koi fish post transportation and to identify best dosage of bandotan leaf on koi fish tranport medium to decrease the blood glucose of koi fish post transportation. Research method used was experimental. Treatment used was providign different bandotan leaf dossage: A $(0 \mathrm{~g} / \mathrm{L}), \mathrm{B}(0.45$ $\mathrm{g} / \mathrm{L}), \mathrm{C}(0,9 \mathrm{~g} / \mathrm{L}), \mathrm{D}(1.35 \mathrm{~g} / \mathrm{L})$ and $\mathrm{E}(1.8 \mathrm{~g} / \mathrm{L})$ and each treatment was repeaetd four times. Main parameter observed in this research was koi fish blood glucose every eight hours for twenty four hours and supporting parameter consisted of: water quality and fish mortality rate. Then the data obtained were prepared using ANOVA, continued by Dunnett Test and then by Duncan's Multiple Distance. Research result shwoed that bandotan leaf supply in transport medium had no effect on koi fish blood glucose post transportation and highest dosage of bandotan leaf in transport medium on blood glucose of koi fish post transportation was $0.45 \mathrm{~g} / \mathrm{L}$.
\end{abstract}

Keywords : koi fish, blood glucose, stress

\section{Pendahuluan}

Transportasi dapat menyebabkan tekanan pada sistem kekebalan, menghasilkan berbagai macam penyebab meningkatnya penyakit dan kematian pada ikan ikan (Zonneveld et al., 1991). Kematian akibat transportasi dan penanganan pasca transportasi mencapai $30-40 \%$. Kematian terjadi beberapa hari setelah transportasi (Yosmaniar dan Azwar, 2006). Selama transportasi, ikan mengalami stres akibat kepadatan tinggi dan penurunan kualitas air (Barton et al., 1980 dan Erikson et al., 1997 dalam Dobsikova et al., 2009). Stres dapat meningkatkan glukosa darah. Pengukuran kadar glukosa darah dapat digunakan sebagai parameter stres yang sederhana, efektif dan memadai untuk berbagai macam stressor (Darwisito, 2006). Tanaman bandotan memiliki efek Ca blocking (Achola dan Munenge, 1998; Okunade, 2002; Kamboj dan Saluja, 2010) ) yang diharapkan dapat mengurangi terjadinya proses glikogenolisis dan glukoneogenolisis. Efek Ca blocking terjadi di retikulum endoplasma (Indah, 2004) pada otot polos (Okunade, 2002). Penelitian ini bertujuan untuk mengetahui pengaruh daun bandotan ( $A$. conyzoides) dalam media transportasi terhadap kadar glukosa darah ikan koi (C. carpio) pasca transportasi dan mengetahui dosis terbaik pemberian daun bandotan (A. conyzoides) pada media tranportasi ikan koi (C. carpio) untuk menurunkan kadar glukosa darah ikan koi $(C$. carpio) pasca transportasi

\section{Metodologi}

Penelitian ini dilaksanakan pada tanggal 1-7 Maret 2011. Penelitian dilaksanakan di dua tempat, yaitu di Dusun Tirto, Desa Paremono, Kecamatan Mungkid, Kabupaten Magelang, Jawa Tengah untuk pengambilan ikan dan perlakuan transportasi serta Laboratorium Budidaya Perikanan Fakultas Teknik dan Ilmu Kelautan Universitas Hang Tuah Surabaya untuk pengambilan data glukosa darah ikan. Metode penelitian yang digunakan dalam penelitian ini adalah metode eksperimental. Perlakuan yang digunakan adalah dosis daun bandotan yang berbeda, yaitu A $(0 \mathrm{~g} / \mathrm{L}), \mathrm{B}(0,45 \mathrm{~g} / \mathrm{L}), \mathrm{C}(0,9 \mathrm{~g} / \mathrm{L}), \mathrm{D}(1,35$ $\mathrm{g} / \mathrm{L})$ dan $\mathrm{E}(1,8 \mathrm{~g} / \mathrm{L})$ masing-masing perlakuan diulang sebanyak empat kali. Parameter utama yang diamati dalam penelitian ini adalah kadar glukosa darah ikan koi yang diukur setiap delapan jam selama dua puluh empat jam setelah transportasi. Parameter pendukung terdiri dari kualitas air dan tingkat mortalitas 
Tabel 1. Nilai rata-rata kadar glukosa darah ikan koi (C. carpio) sebelum transportasi dan pasca transportasi

\begin{tabular}{|c|c|c|c|c|}
\hline \multirow{2}{*}{ Perlakuan } & \multicolumn{4}{|c|}{ Kadar glukosa darah ikan koi jam ke- } \\
\cline { 2 - 5 } & 0 & 8 & 16 & 24 \\
\hline Pra & $91,75 \pm 10,773^{\mathrm{a}}$ & $91,75 \pm 10,773^{\mathrm{a}}$ & $91,75 \pm 10,77^{\mathrm{ab}}$ & $91,75 \pm 10,773^{\mathrm{a}}$ \\
Pasca: & & & \\
A & $214,25 \pm 92,288^{\mathrm{a}}$ & $115,00 \pm 46,783^{\mathrm{a}}$ & $96,50 \pm 18,37^{\mathrm{ab}}$ & $71,00 \pm 8,406^{\mathrm{a}}$ \\
B & $127,20 \pm 23,778^{\mathrm{a}}$ & $137,75 \pm 46,700^{\mathrm{a}}$ & $93,25 \pm 18,33^{\mathrm{b}}$ & $76,50 \pm 9,579^{\mathrm{a}}$ \\
C & $132,25 \pm 9,464^{\mathrm{a}}$ & $99,00 \pm 26,991^{\mathrm{a}}$ & $126,50 \pm 10,603^{\mathrm{a}}$ & $104,50 \pm 15,867^{\mathrm{a}}$ \\
D & $102,75 \pm 23,092^{\mathrm{a}}$ & $143,75 \pm 16,023^{\mathrm{a}}$ & $77,00 \pm 10,551^{\mathrm{b}}$ & $103,00 \pm 14,944^{\mathrm{a}}$ \\
E & $118,00 \pm 20,166^{\mathrm{a}}$ & $121,00 \pm 36,485^{\mathrm{a}}$ & $74,50 \pm 3,926^{\mathrm{b}}$ & $88,25 \pm 16,67^{\mathrm{a}}$ \\
\hline
\end{tabular}

Keterangan : superskrip yang berbeda menunjukkan adanya pengaruh yang berbeda nyata perlakuan $(p<0,05)$ terhadap kadar glukosa darah

ikan. Pengukuran kualitas air meliputi suhu, $\mathrm{pH}$ dan oksigen terlarut. Data yang diperoleh, diolah dengan menggunakan Analysis of Variant (ANOVA), kemudian dilanjutkan dengan Uji Dunnett guna mengetahui interaksi antara masing-masing perlakuan dengan kontrol berdasarkan waktu pengambilan data, kemudian dilanjutkan dengan uji Jarak Berganda Duncan untuk mengetahui perlakuan terbaik pada masing-masing perlakuan.

\section{Hasil dan Pembahasan}

Pengukuran kadar glukosa darah dilakukan sebelum transportasi dan pasca transportasi. Pemberian daun bandotan ( $A$. conyzoidez) memberikan pengaruh yang tidak berbeda nyata $(\mathrm{P}>0,05)$ terhadap kadar glukosa darah ikan koi pada jam ke-0 sampai dengan jam ke-24 pasca transportasi. Hasil Uji Jarak Berganda Duncan diketahui bahwa pada jam ke16 , perlakuan $C(0,9 \mathrm{~g} / \mathrm{L})$ berbeda nyata dengan perlakuan D $(1,35 \mathrm{~g} / \mathrm{L})$ dan $\mathrm{E}(1,8 \mathrm{~g} / \mathrm{L})$, akan tetapi perlakuan $\mathrm{C}(0,9 \mathrm{~g} / \mathrm{L})$ tidak berbeda nyata dengan perlakuan A $(0 \mathrm{~g} / \mathrm{L})$ dan B $(0,45 \mathrm{~g} / \mathrm{L})$. Nilai rata-rata kadar glukosa darah ikan koi sebelum transportasi dan pasca transportasi dapat dilihat pada Tabel 1. Peningkatan kadar glukosa darah terjadi mulai dari waktu pengamatan pertama. Peningkatan kadar glukosa darah tertinggi terjadi pada perlakuan A (0 g/L) sedangkan peningkatan kadar glukosa darah terendah terjadi pada perlakuan $\mathrm{D}(1,35$ $\mathrm{g} / \mathrm{L})$.

Penghitungan mortalitas ikan koi selama penelitian dilakukan tiap 8 jam selama 48 jam pasca transportasi. Presentase mortalitas ikan koi (C. carpio) pasca transportasi dapat dilihat pada Tabel 2. Mortalitas ikan koi tertinggi terjadi pada perlakuan $\mathrm{C}(0,9 \mathrm{~g} / \mathrm{L})$ sebanyak $77,5 \%$ sedangkan mortalitas ikan koi terendah terjadi pada perlakuan A (kontrol) sebanyak
52,5\%. Kematian ikan koi pasca transportasi dimulai sejak 0 jam pasca transportasi. Hasil penelitian menunjukkan bahwa pemberian daun bandotan selama transportasi ikan koi memberikan pengaruh yang berbeda nyata terhadap tingkat mortalitas ikan koi pasca transportasi pada perlakuan $\mathrm{C}(0,9 \mathrm{~g} / \mathrm{L})$.

Tabel 2. Presentase mortalitas ikan koi ( $C$. carpio) pasca transportasi

\begin{tabular}{|l|c|}
\hline Perlakuan & Mortalitas $(\%)$ \\
\hline $\mathrm{A}(0 \mathrm{~g} / \mathrm{L})$ & 52,5 \\
$\mathrm{~B}(0,45 \mathrm{~g} / \mathrm{L})$ & 57,5 \\
$\mathrm{C}(0,9 \mathrm{~g} / \mathrm{L})$ & 77,5 \\
$\mathrm{D}(1,35 \mathrm{~g} / \mathrm{L})$ & 63,7 \\
$\mathrm{E}(1,8 \mathrm{~g} / \mathrm{L})$ & 62,5 \\
\hline
\end{tabular}

Parameter kualitas air yang digunakan dalam penelitian ini adalah suhu, oksigen terlarut dan $\mathrm{pH}$. Data kualitas air diambil sebelum transportasi dan pasca transportasi. Suhu air berkisar antara $23-25^{\circ} \mathrm{C}$, oksigen terlarut berkisar antara 3-7 ppm dan $\mathrm{pH} 7$.

Berdasarkan hasil penelitian pengaruh penggunaan larutan daun bandotan terhadap kadar glukosa darah ikan koi pasca transportasi dapat diketahui bahwa kadar glukosa darah ikan koi sebelum ditransportasikan adalah 91,75 $\mathrm{mg} / \mathrm{dL}$. Nilai glukosa ini lebih rendah dibandingkan dengan nilai kadar glukosa darah menurut Field et al. (1943) dalam Stoskopf (1993) yaitu, kadar glukosa darah common carp adalah $111 \mathrm{mg} / \mathrm{dl}$. Rendahnya nilai glukosa darah ikan koi sebelum ditransportasikan antara lain disebabkan oleh dilakukan pemberokan ikan koi yang akan ditransportasikan. Hal ini bertujuan untuk mengosongkan makanan yang ada di dalam lambung dan usus ikan sehingga selama pengangkutan aktivitas metabolisme ikan akan tetap rendah dan efek keracunan yang 
disebabkan karena penimbunan kotoran hasil metabolisme makanan menjadi berkurang (Sufianto, 2008).

Waktu pengamatan pertama (jam ke-0 pasca transportasi) terjadi peningkatan kadar glukosa darah pada semua perlakuan. Peningkatan glukosa darah tertinggi terjadi pada perlakuan A $(0 \mathrm{~g} / \mathrm{L})$, yaitu dari $91,75 \mathrm{mg} / \mathrm{dL}$ menjadi $214,25 \mathrm{mg} / \mathrm{dL}$ dan peningkatan glukosa terendah pada perlakuan D $(1,35 \mathrm{~g} / \mathrm{L})$. Peningkatan kadar glukosa darah (hiperglikemia) ikan koi pasca transportasi dimungkinkan terjadi akibat stres pada ikan selama proses transportasi (Svobodova et al., 1999). Kadar glukosa darah ikan koi pada perlakuan A (0 g/L) mengalami peningkatan yang tinggi dibandingkan dengan glukosa darah ikan koi pada perlakuan B $(0,45 \mathrm{~g} / \mathrm{L}), \mathrm{C}(0,9$ $\mathrm{g} / \mathrm{L}), \mathrm{D}(1,35 \mathrm{~g} / \mathrm{L})$ dan $\mathrm{E}(1,8 \mathrm{~g} / \mathrm{L})$. Hal ini dikarenakan daun bandotan memiliki senyawasenyawa kimia antara lain atsiri, flavanoid, kumarin, kromen dan alkaloid (Okunade, 2002; Kamboj dan Ajay, 2008). Senyawa-senyawa kimia yang ada dalam daun bandotan memiliki efek Ca blocking (Okunade 2002; Kamboj dan Ajay, 2008) yang dapat menghambat terjadinya proses glikogenolisis di hati (Maunah, 2010) sehingga peningkatan kadar glukosa darah ikan koi tidak terlalu tinggi.

Hastuti dkk., (2003) menyatakan bahwa mekanisme terjadinya perubahan performa glukosa darah selama stres adalah adanya stressor akan diterima oleh organ reseptor kemudian informasi tersebut disampaikan ke otak bagian hipotalamus melalui sistem saraf. Selanjutnya, sel kromaffin menerima perintah melalui serabut saraf simpatik untuk mensekresikan hormon katekolamin. Hormon ini akan mengaktivasi enzim-enzim yang terlibat dalam katabolisme simpanan glikogen hati dan otot serta menekan sekresi hormon insulin, sehingga glukosa darah mengalami peningkatan.

Saat yang bersamaan, hipotalamus otak mensekresi CRF (corticoid releasing factor) yang meregulasi kelenjar pituitari untuk mensekresi ACTH (Adenocorticotropik hormone), MSH (Melanophore-Stimulating hormone) dan $\beta$-End ( $\beta$-endorphin). Hormon tersebut akan meregulasi sekresi hormon kortisol dari sel interrenal. Kortisol akan menggertak enzim-enzim yang terlibat dalam glukoneogenesis yang menghasilkan peningkatan glukosa darah yang bersumber dari non karbohidrat (Hastuti., 2003).

Mortalitas ikan koi pasca transportasi tertinggi terjadi pada perlakuan C $(0,9 \mathrm{~g} / \mathrm{L})$. Salah satu penyebab kematian pada ikan adalah akibat stres pasca transportasi. Transportasi selalu mengakibatkan kematian ikan yang seketika pada perlakuan tersebut atau sesudahnya sebagai akibat tidak berfungsi normalnya osmoregulasi atau terinfeksi penyakit (Yosmaniar dan Azwar, 2006). Selain itu, kematian ikan koi yang diberi perlakuan dimungkinkan akibat adanya senyawa saponin yang terkandung dalam daun bandotan. Penggunaan saponin berlebih dapat menyebabkan iritasi pada selaput lendir, dapat menghemolisis butir darah merah, bersifat racun bagi hewan berdarah dingin dan banyak digunakan sebagai racun ikan.

Oksigen $\left(\mathrm{O}_{2}\right)$ sebagai bahan pernafasan dibutuhkan oleh sel untuk berbagai reaksi metabolisme. Oleh karena itu, kelangsungan hidup ikan sangat ditentukan oleh kemampuan memperoleh $\mathrm{O}_{2}$ yang cukup dari lingkungannya (Sufianto, 2008). Kandungan oksigen terlarut ikan koi selama penelitian berkisar antara 3-7 ppm. Piper et al (1982) dalam Sufianto (2008) menyatakan, kandungan oksigen terlarut media pengangkutan harus lebih besar dari $7 \mathrm{mg} / \mathrm{L}$. Rendahnya kandungan oksigen terlarut media pengangkutan antara lain disebabkan oleh tingginya kepadatan ikan yang ditransportasikan (20 ekor/L). Nilai pH ikan koi selama penelitian adalah 7. Hal ini sesuai dengan $\mathrm{pH}$ optimal untuk pengangkutan, yaitu berkisar antara 6-7 dan sesuai dengan nilai $\mathrm{pH}$ air optimal bagi kehidupan ikan, yaitu berkisar antara $6-7$ (Sufianto, 2008).

\section{Kesimpulan}

Dosis tertinggi pemberian daun bandotan (A. conyzoides) yang dapat digunakan dalam media transportasi adalah 0,45 g/L.

\section{Daftar Pustaka}

Achola, K.J dan R.W Munenge. 1998. Bronchodilating and Uterine Activities of Ageratum conyzoides Extract. Pharmaceutical Biology, 36(2):93-96.

Darwisito, S. 2006. Kinerja Reproduksi Ikan Nila (Oreochromis niloticus) yang Mendapat Tambahan Minyak Ikan dan Vitamin E dalam Pakan yang Dipelihara pada Salinitas Media Berbeda. Tesis. Pascasarjana. Institut Pertanian Bogor. Bogor. 165 hal.

Dobsikova, R., Z. Svobodova., J. Blahova., H. Modra dan J. Velisek. 2009. The Effect of Transport on Biochemical and Haematological Indices of Common Carp (Cyprinus carpio L.). Czech J. Anim. Sci., 54 (11): 510-518. 
Hastuti, S., E. Supriyono., I. Mokoginta dan Subandiyono. 2003. Respon Glukosa Darah Ikan Gurami (Osphronemus gouramy, Lac.) terhadap Stres Perubahan Suhu Lingkungan. Jurnal Akuakultur Indonesia, 2(2): 73-77.

Indah, M. 2004. Mekanisme Kerja Hormon. http://repository.usu.ac.id. 24/09/2010. 26 hal.

Kamboj, A dan A. K. Saluja. 2010. Ageratum conyzoides L.: A Review on its Phytochemical and Pharmacological Profile. International Journal of Green Pharmacy: 59-68.

Liza. 2010. Otak Manusia, Neurotransmiter dan Stress. Dinas Kesehatan Kabupaten Cirebon. Cirebon. 20 hal.

Maunah, D. 2010. Metabolisme Zat Gizi Makro. http://elearning-1.esaunggul.ac.id. 11/04/2011. 54 hal.

Okunade, A. L. 2002. Ageratum conyzoides L. (Asteraceae). Fitoterapia, 73:1-16.

Sufianto, B. 2008. Uji Transportasi Ikan Mas koki (Carassius auratus Linnaeus) Hidup Sistem Kering Dengan Perlakuan Suhu dan Penurunan Konsentrasi Oksigen. Tesis. Program Pasca Sarjana. Institut Pertanian Bogor. Bogor. 135 hal.

Svobodova, Z., P. Kalab., B. Vykusova., J. Kolarova dan D. Janouskova. 1999. The Effect of Handling and Transport on the Concentration of Glucose and Cortisol in Blood Plasma of Common Carp. ACTA VET. BRNO, 66: 265274

Yosmaniar dan Z. I. Azwar. 2006. Studi Teknik Transportasi dan Penanganan Pasca Transportasi Ikan Betutu (Oxyeleotris marmorata Blkr.) untuk Menekan Mortalitas. Makalah pada Prosiding Seminar Nasional Ikan IV. Jatiluhur. 29-30 Agustus 2006. hal 123-126.

Zonneveld, N., E. A Huisman dan J. H. Boon. 1991. Prinsip-Prinsip Budidaya Ikan. Gramedia Pustaka Utama. Jakarta. hal 164-298. 